\title{
FROM THE WEST TO THE KREMLIN AND BACK
}

\author{
DEVELOPMENT PATHS OF FOREIGN \\ PRODUCTS ON RUSSIAN TELEVISION
}

\author{
Elena Prati \\ Università Cattolica del Sacro Cuore \\ elena.prati@unicatt.it
}

\begin{abstract}
In the last years the arrival of international OTT providers and the development of national online digital platforms have deeply changed the Russian television environment. The constant need of both national self-affirmation and new contents has led to the development of different paths of content creation. In particular, foreign ready-made content follow three paths: adaptation, localization and 'Russification', depending on their genre. The 'Russification' process is the most peculiar one and consists in the re-creation of a foreign product with local resources. The article will give the reader some key-concept to understand some of the most popular 'Russification' attempts, from the very first (The Nanny) to the most contemporary (Adaptation).
\end{abstract}

Keywords: TV series, remake, Russian television, global TV

\section{Introduction}

Nowadays television plays a key-role in the Russian mass communication media system. ${ }^{1}$ The industry defines itself as a dynamic sector in continuous evolution and the development of digital technologies brought an unprecedented market growth and the number of channels, as remarked by PWC's focus issue on the Russian market. ${ }^{2}$ But, along with this growth, there was a lack of new ideas and programs. ${ }^{3}$ This situation forced Russian producers to deal with their foreign colleagues and to buy and adapt their formats for the national market.

Today, TV programs based on foreign format adaptations are an integral part of the Russian schedules. Furthermore, national channels' tendency is more to import products than to export them. Adaptation for the Russian audience has always been a producers' responsibility, based on their intuition. For this reason, there are no general characteristics or rules about a product performance on the national market. This is not a clear nor standard process.

In Russia, channels can be divided into terrestrial (DTT) and non-terrestrial (satellite, IPTV and cable). However, due to the geographical conformation of the country, it is not possible to consider terrestrial channels 'exclusively terrestrial'. Many regions are indeed reached only by satellite signal and, for this reason, according to the Russian law, a channel can be considered federal when it is aired in five different regions. The most popular federal channels are Perviy Kanal, Rossiya and NTV and these are often used to broadcast fundamental information to the public. 
The Russian television system presents many similarities to the European one, concerning PBS and commercial channels. Public and commercial channels air a wide variety of programs, including movies, TV series, TV shows, information and research programs. What these channels have in common is that the TV series aired are dated and do not interest young adults; in particular, those who have generally already enjoyed this content on different platforms. On the other hand, commercial channels are structured to attract a specific audience, in order to maximize incomes. ${ }^{4}$ For example, there are thematic channels for students like Shkol'niki TV; channels dedicated to male young adults, that mostly air anime and cartoons, like $2 \times 2$, and channels literally dedicated to housewives, like Domashnyi.

The analogue cable has been the most common type of reception in Russia until 2019 when the analogic signal was officially turned off (much later compared to the EU). Russian pay-TVs are divided into two macro-categories, depending on the approach to assessing the number of users/subscribers. The first one is specific of the 1990s (when pay-TVs in Russia essentially took place): at that time, in the largest Russian cities, operators took over the management of the analogue connection of entire apartment blocks at no charge. ${ }^{5}$ All the flats would then receive a better signal and more channels from pay-TV, for a higher aerial communal standing charge, but without a subscription. Nevertheless, these households are considered into the total amount of pay-TV services. The second approach is more related to the contemporary market shape. It includes, indeed, only those households which have a contract with an operator. Geographically speaking, Russian pay-TVs market shows two different tendencies: the highest saturation is located in the Central and Northwestern districts, while the fastest growth rates are observed in Siberia, Central Russia and Far East.

Although its capillary distribution, analysts register a stagnation in the cable pay-TV segment, due to a great expansion of satellite and IPTV. In 2011 the first "online cinema" service was launched in Russia, Okko, that now includes 35.000 titles (films, cartoons and TV series) and has 17 million subscribers and 1,5 million viewers per month. In 2012 iTunes and Google Play launched in Russia and in 2013 arrived Amediateka, the official Russian distributor for HBO contents. Starting from 2014-2015 Russian mobile networks started to develop their own OTT platforms: MTS TV and Megafon TV were the first companies offering access to TV channel packages and film catalogues, including the libraries of the former independent VoD services Stream and Trava.ru as part of the mobile TV service. In 2016 arrived Netflix and Amazon Prime Video and, with them, the legal framework for foreign ownership of TV channels and the operators in Russian territory completely changed.

Conceptually, I will outline my theoretical framework by historically placing Western products (in particular, TV series) in the Russian schedules, describing how and when they arrived and in which cultural and economic environment. Then, I will map how a foreign product is 'treated' in order to be broadcast on television and argue that different treatments lead to different results, writing about the quality of the product and its success among the public. In this part I will also present to the reader some examples of products broadcast over the years on Russian television. This will be followed by a case analysis presenting an example of a successful program and of an unsuccessful product, that will be examined more thoroughly. This will be followed by concluding remarks.

\section{Importing Foreign Programmes: From "Russification" to the Contemporary 'National Answers"}

In the history of Russian television, foreign content started being broadcast after the dissolution of the Soviet Union in 1991. There are two reasons why Western content arrived in Russia so late: one is socio-political, the other is cultural.

Before 1991, the Soviet Union was evidently closed to the West and its television was thought of as a propaganda instrument. ${ }^{6}$ TV only had to spread Soviet information and secondly entertain: schedules included very few (and bad quality) programs, such as news, talk shows and crime series. The rise of television contributed in maintaining the Soviet ideal and still has this role in modern Russia, as highlights Josh Nadeau. ${ }^{7}$ During Perestroika (the last period 
of the USSR, was characterized by an initial opening to the Western world), though, the first foreign films were shown on TV: for example, in 1986 the Italian movie La Piovra seduced the Russian public.

After the dissolution of the USSR everything changed and, from a socio-political point of view, Russia opened to the West and started importing new TV programs, responding to a national need for content, because of the birth of commercial television. In the first years it was mostly imported unscripted formats, with a preference for game and 'alea' shows; then, in the 2000s, TV serials started being imported and a new era for Russian television began.

As Zvereva states, the closure of successful independent channels and TV-journalist projects in the 1990s, which occurred within the framework of underdeveloped cable networks and the absence of other alternative options, led to the disappearance of political discussion shows. ${ }^{8}$ TV channel directors wanted to achieve economic success and this led to the rise of entertainment-driven projects. Gradually the viewers got used to the foreign consumeristic world presented by the increasing advertising and began to pursue a higher quality of life, especially the new middle class, who did not have to concern themselves about survival. This shift is shown well by the new TV serials produced by Amedia, Moya Prekrasnaya Nyanya (My Fair Nanny, 2004-2009) and Ne Rodis' Krasovoy (Better Be Born Lucky Than Fair, 2005), that contributed to the construction of new norms of everyday life, in line with this new consumer-oriented television. They were followed by a number of 'lifestyle programs' that became incredibly popular, such as Snimite eto nemedlenno! (Take It Off Immediately!, 2004) and Shkola remonta (The School of Décor, 2011-).

These new programs opened to a completely unknown world for the viewer, who had to be guided into it. What the viewer did not know, was not only the geography of a city or the stereotypes connected to a specific country, but also a completely new way of living.

From a cultural point of view, the importation of foreign serials led to the need of re-elaboration, in order to make them understandable and remarkable for Russian spectators. This process was (and still is nowadays) made through three different paths: adaptation, localization and 'Russification'.

The concept of 'adaptation' is generally considered as an intersemiotic translation from a medium (usually a tale or a novel) to another (usually a movie) of the same narrative content. ${ }^{9}$ But Linda Hutcheon in A Theory of Adaptation defines the adaptation as "a recognized transposition of one or more recognizable works; a creative and interpretative act of appropriation and recover". ${ }^{10}$ This means that a translated copy that becomes a representation of the original can be considered an adaptation.

On the other hand, localization is the transposition of a global format (both scripted or unscripted) into the destination culture. It is a product that contains meanings, inferences and implications concerning daily life, political institutions and traditions that must not be taken for granted. ${ }^{11}$ The latter one is the most significant and peculiar in the history of Russian television and was almost naturally born, due to economic and cultural aspects to be preserved.

'Russification' begins as a localization but ends in a process of remake of a foreign product, where the general storyline is maintained while the setting, cast and cultural details of the plot are changed to fit the national market and public expectations. It can be considered a pioneering idea of a scripted format, but, in reality, mostly economic reasons led to its birth.

The first foreign products arrived on Russian TV after the dissolution of the Soviet Union and the birth of the Russian Federation, in an economically devastated country where each aspect of everyday life had to be re-thought and re-organized. Television started being considered an entertaining instrument and schedules needed to be diversified, through the broadcast of news, game, talk and rudimentary talent shows and through TV serials.

Economically speaking, remaking a foreign product was far cheaper than buying its rights of reproduction. In these conditions 'Russified' products were born, with a subtle aura of illegality. Culturally speaking, the Russian Federation had just opened to the West, so many aspects and details told in the foreign (especially American) products were 
completely unknown to the public and, consequently, incomprehensible. Although already part of the collective imaginary in Europe and the US, these aspects had to be changed for the Russian public, not only to allow them to be understood, but also to be successful. As a representation of a new lifestyle, aesthetic symbols of wellness and richness had to be desirable for the viewers and so they had to be part of the Russian culture of that time. Showing a more or less expensive foreign car, such as a Ford, would not have given a sense of desire to the public, as Fords were not available or known in Russia. They simply had to be substituted with their Russian equivalent.

In these conditions, remakes became part and tradition of Russian television history. Some of the most popular Russian remakes concern equally popular American TV series, but their success was not always the same. Among these 'Russified' products we can list both sitcoms and dramas.

One everlasting success is Voroniny (2009-2018), the Russian remake of American Everybody loves Raymond (CBS, 1996-2005) on channel STS, the most important on DTT for American sitcoms. It started being broadcast in 2009 and, contrary to the original, it is still on air on Russian channels. The first 10 series were based on the originals; the following ones have been written from scratch, with the initial help of the American creators and writers. Voroniny now counts 23 series and this number represents a very typical aspect of Russian television industry: in a year multiple seasons of one title can be produced and broadcast.

In an organizational perspective, all the episodes of a series are shown subsequently, not creating a weekly schedule, but a daily one on the same channel at the same time every day until they are all seen. Furthermore, in general, Russian series have more episodes per season than Western ones: Voroniny counts 455 episodes so far. Its success is determined by the capacity of writers and creators to maintain the general wit of the original series, changing the family habits in order to better represent a typical Russian family. Otherwise, the Barones' habits and characteristics would have been completely incomprehensible to a Russian viewer. Thanks to its success, a documentary about the behind the scenes of the Russian exportation and remake has been produced and broadcast with the title Exporting Raymond (2010). The documentary shows not only the production moments, but also American and Russian writers and creators working together, especially accepting compromises, to create the best product for everyone. A series that will not lose its original irony, and still be able to represent the middle class of the national market where it is broadcast.

Another American sitcom remade in the Russian Federation, but with far less success, is Schastlivy vmeste (Married... with children - FOX, 1987-1997). It was broadcast on TNT channel, another DTT channel whose programming is based on American shows, but with a lower audience compared to STS, from 2006 to 2013. The Russian version is temporarily set after the dissolution of the USSR and tells of the birth of the middle-class in Russia. It is made of 6 seasons, with a total of 365 episodes. The original series is composed of 11 seasons, that in Schastlivy vmeste were condensed in the first three seasons. This sitcom is an example of being unsuccessful because there were many socio-cultural items of the original series that have not been 'translated' into the Russian one. For example, a two-floor apartment is now a house that only a rich family living in the city center of a big city could afford in Russia, not a middle-class family in the first years after the dissolution of the USSR. Another point against the Russian remake is that between 1990s and 2000s channel TV-6 Russia aired the original season, that, even if culturally difficult to understand for the Russian public (as many typical American aspects assumed for the European public were completely unknown), it was still more credible than the Russian version.

Two interesting examples of drama remakes are the ones for House M.D. (FOX, 2004-2012), Firstly, Doktor Tyrsa (2010), which was an unofficial remake that aired only one season in 2010 and closed due to low ratings and public dissatisfaction. And secondly, Doktor Richter (2017-), which is the official Russian remake, that aired in 2017 on Rossija 1 and has two seasons.

Over the last few years a new development path has started in the Russian TV industry. As many OTT players, both national and international, have appeared in the television environment and, consequently, a lot of foreign content has become available for the Russian public, the 'Russification' process has reduced its importance to give space to new content. 
Especially in the last two years, Russian TV studios have started producing a 'national answer' to many foreign shows involving Russia in their plots. It all started with the creation of The Americans (FX, 2013-2018), where the protagonists are two Russian KGB spies living in the US during Cold War. As a national remake would not be possible, a Russian answer to it has been created, in order to give the world their version of the story. The Russian answer to The Americans is entitled Adaptatsiya (Adaptation) and it aired in 2017 and 2018 on the TNT channel, counting two seasons so far. It is the story of an American spy perfectly speaking Russian, but not completely aware of the culture and the habits, that has to seep in Gazprom Company. It has an ironic subtext, absent in The Americans, and many referrals to the contemporary political situation (not without a critical streak). In general, its plot is based on the idea that Russians are smart and winners - Americans are naive and losers.

Covering the current situation, the latest news is that next year channel NTV will show the Russian answer to HBO Chernobyl (2019), since Russian pro-government press declared that the show was "a caricature, not the truth". ${ }^{12}$ The story is based on the idea that the nuclear disaster in Pripyat was caused by a CIA agent. Although there is no evidence of it even in the official documentation, show director Alexei Muradov declared: "One theory holds that Americans had infiltrated the Chernobyl nuclear power plant and many historians do not deny that, on the day of the explosion, an agent of the enemy's intelligence services was present at the station"13. As of today, despite the critics and the government blame, Chernobyl is available on Russian OTT Amediateka, whose claim is 'Home of HBO'.

\section{Case Analysis: The Remakes of The Nanny and How I Met Your Mother. What Worked, What Did Not?}

As already mentioned in the previous paragraph, many examples of 'Russification' can be found in the history of Russian TV. Some of them successful, some of them not, but each of them is important to understand what worked, what did not and why.

One of the most successful and popular series in absolute terms in Russia was Moya Prekrasnaya Nyaya (My Fair Nanny), a remake of the worldwide popular American series The Nanny (CBS, 1993-1999). It was the very first sitcom aired in the Russian Federation and it was broadcast on STS channel from 2004 to 2006, with a new season in 2008. It was produced by Amedia and Sony Pictures and the executive producer was Fran Drescher herself, as in the original one. It is divided into 7 seasons, one more compared to the The Nanny, for a total of 173 episodes.

As The Nanny obtained a great critical success worldwide, many national versions of it have been created over the years, not only in Russia but also in Argentina, Chile, Ecuador, Greece, Indonesia, Italy, Mexico, Poland and Turkey. In Moya Prekrasnaya Nyaya the storyline has not been changed, but producers and writers have teamed up to best localize the most important cultural aspects (including setting, food, jokes and clothing) to create a product that could work for the public.

Since the Russian public at the time was not used to the American environment and stereotypes as it was to the European one, Moya Prekrasnaya Nyaya is located in Moscow (instead of New York), where the difference between upper and lower class works perfectly. Another unchanged aspect regards the professions: the male character is still a theatrical producer and the female character is a door-to-door make-up seller. But, on the contrary, names have been deeply localized: Maxwell Sheffield became Maksim Viktorovich Shatalin and Fran Fine became Viktoria Vladimirovna Prutkovskaya. Viktoria lives in the suburbs and comes from Ukraine, that is a very typical expedient narrative. The comparison with the close Ukraine is a fundamental part of the majority of the stories, while the Jewish line was cancelled as it is not so much into the Russian culture, as in the American one. The geographical comparison between Russia and Ukraine is more similar to the narrative used in the Italian version of The Nanny, La Tata. Here the female protagonist is called Francesca and she has Italian origins, representing the Italian community in New York. 
E. Prati, From the West to the Kremlin and Back.

Another 'topos' that cannot be ignored is love. Most of the romantic Russian stories (especially those broadcast on television) follow the idea of 'the rich man marrying the poor but beautiful woman'. This is a storyline present even in the original series, but from the fifth season. Russian writers introduced it early on, in order to capture the interest of women whose audience numbers were bigger than the men's, but whose preferences did not include sitcoms, up to that moment.

The seventh season was created from scratch by Russian writers and producers, working together with the American team. They developed a whole new season, but they wanted to end the series as the original one, so at the beginning of the seventh season the viewer discovers that the end of the sixth was only a dream and the story continues.

Even the visuals played a very important role in the creation and success of the series: while the theme has not been changed, from the very first scene the environment is different and typically Russian. The clothing, the architecture, the store signs have all been changed to fit the Russian imaginary, to create a connection between the reality of everyday life and the series.

One of the most well-known failures in the history of Russian remakes is represented by Kak ya vstretil vashu mamu, a remake of the American sitcom How I Met Your Mother (CBS, 2005-2014). It is an unsuccessful example, because it is based on a literal translation of the original version, starting from the title, which is the exact transposition of the English one.

In this case, writers and producers have maximized their efforts to create a product that was totally similar to the original, starting from a visual point of view. They chose actors that physically resembled the American ones and re-created the setting in order to make is as similar as possible to the original, ignoring that many items (such as those machines where you can catch stuffed animals) are not part of the Russian culture.

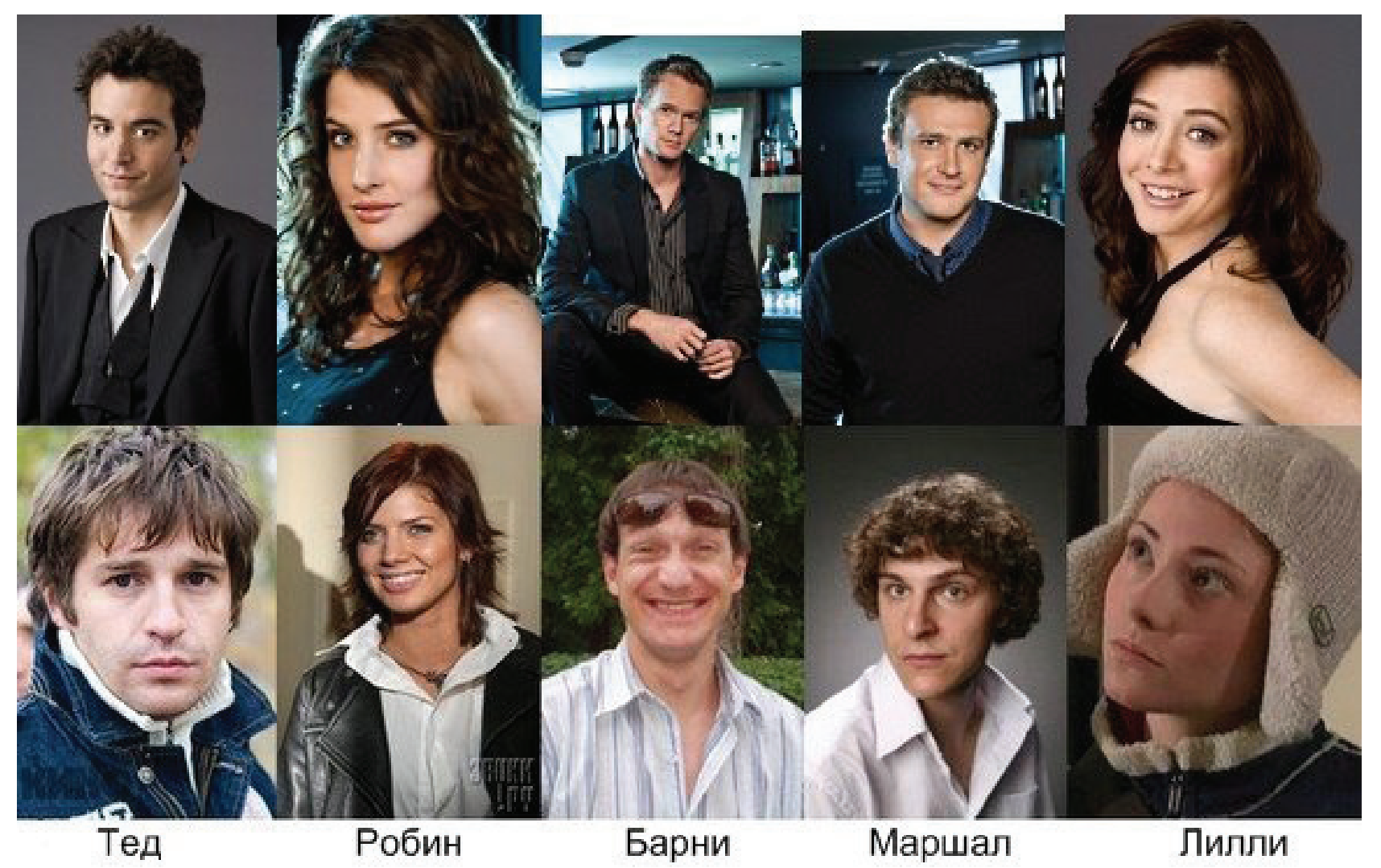

Figure 1. A physical comparison among Russian and American actors. 
Kak ya vstretil vashu mamu was aired on the STS channel in 2010, but the original How I met your mother was aired in the same period on Pervyj Kanal. As many years have passed from the arrival of the first American sitcom on TV, viewers are now more used to the American style and the possibility to compare the series declared the death of the Russian one. Critics were so negative that a petition was opened by the fans to close down the series.

The comparison evidenced that many aspects connected to acting, translation and setting did not work in the Russian version, because it was too close to the original product and not to the reference culture.

From a linguistic point of view, jokes have been literally translated from English, but they do not have sense in Russian. This prevents a non-speaking English viewer from understanding the dialogue and an English-speaking viewer from appreciating the dialogue, because it cannot be understood.

From a narrative point of view, geographical references have been changed without a logic: in episode 'Sweet taste of liberty,' 1: 3, Ted and Barney are in Philadelphia and call Marshall to join them from New York City - the distance of 96 miles is believable if travelled by car during the night. In the Russian equivalent episode 'The taste of a cultural capital,' 1: 3, Dima and Jura are in St. Petersburg and call Pasha to join them from Moscow. He gets in the car and reach them in a couple of hours, but the distance between the two cities is 714 kilometers.

In Kak ya vstretil vashu mamu the Ukranian 'topos' too, is as an example of a successful transposition. In episode 'Aldrin Justice,' 2: 6, Lily is working in an Hawaiian restaurant and, while serving her friends, they make fun of her with jokes about Hawaii. In the equivalent Russian episode, Lyusa is working in a Ukranian restaurant and her friends joke around the fact that Russians do not pay for gas coming from Ukraine. The result is funny and believable, a real effort to approach the destination culture, but this seems to be more a chance attempt, than a rule.

What has evidently worked in Moya Prekrasnaya Nyaya is the effort of the production to create something understandable and appreciable by the public. Maybe due to the historical moment and the role of the first foreign product adapted for the Russian television, the care taken in producing, writing and adapting the series has led to a national success, still ongoing nowadays. The quality of the writing balances the lack of production resources and the research on the storylines in every episode and season make the series stand out among its peers in the Russian television schedules. Its success is connected to the will of creating a suitable program for the public and not to the exploitation of a globally popular series. These characteristics seems missing in Kak ya vstretil vashu mamu, because the series looks for a maximum similarity to its original, as Vyacheslav Murugov (STS Media executive producer) declares in an interview about the series: "When we worked on this project with GoodStoryMedia producers we decided to make the characters close to the originals". ${ }^{14}$ Even if the program has been submitted to a public who are already used to Western audiovisuals, its resulting 'packaging' was an hybrid that did not match the tastes of nonfamiliar viewers (because it presumed too many details of the American lifestyle) and the tastes of familiar viewers (because it resulted as an 'aspiring' American product while in reality it was not).

\section{Notes}

1. Stephen Hutchings and Natalia Rulyova, Television and Culture in Putin's Russia: Remote Control (London: Routledge, 2009).

2. See report: "Media market in Russia, a future of potential," PWC, Russia, 2015.

3. Vera Zvereva, "Lifestyle Programs on Russian Television," Russian Journal of Communication 3, no. 3-4 (2010): 265-79.

4. Ibid.

5. European Audiovisual Observatory, Yearbook, 2015, www.obs.coe.int

6. Nikolaj Alekseevich Goljadkin, Istorija otechestvennogo i zarubezhnogo televidenija [History of National and Foreign Television] (Moskva: Aspekt Press, 2014). 
E. Prati, From the West to the Kremlin and Back.

7. Josh Nadeau, "Classic Soviet TV: Heroes, enemies and the legacy of the USSR's most popular series," Calvert Journal, September 5, 2017, https://www.calvertjournal.com/articles/show/8910/soviet-tv-classics-heroes-enemies-Stierlitz-populartv-series

8. Zvereva, "Lifestyle Programs on Russian Television", Ibid.

9. Luca Barra, Risate in Scatola [Laughters in a Box] (Milano: Vita \& Pensiero, 2012) 66-8.

10. Linda Hutcheon, A Theory of Adaptation (London: Routledge, 2006), 8.

11. Chiara Giaccardi, I luoghi del quotidiano. Pubblicità e costruzione della realtà sociale [The places of the everyday. Advertisement and construction of social reality] (Milano: Franco Angeli, 1995), 22.

12. Jaime Dettmer, "Russian TV series blames CIA for Chernobyl Nuclear Disaster," Voa News, June 11, 2019, https://www. voanews.com/europe/russian-tv-series-blames-cia-chernobyl-nuclear-disaster

13. Ilya Shepelin, "Putin's Media Struggle to Deal with HBO's Chernobyl", The Moscow Times, June 4, 2019, https://www. themoscowtimes.com/2019/06/04/putins-media-struggle-to-deal-with-hbos-chernobyl-a65866

14. Sergei Obolonkov, "Vyacheslav Mugurov o novinke STS" [Vyacheslav Mugurov about the new STS], Howimet-rus, September 3, 2010, http://howimet-rus.ru/articles/vyacheslav_murugov_o_novinke_sts.php

\section{Biography}

Elena Prati is a PhD student in Foreign Languages and Literature, specializing in television studies, at Università Cattolica del Sacro Cuore in Milan. She has a specialization in Russian and is now studying the distribution of Western television content in the Russian market. 